\title{
Comparison of Biochar Formation from Various Agricultural By-Products Using FTIR Spectroscopy
}

\author{
Yongliang Liu ${ }^{1}$, Zhongqi $\mathrm{He}^{1} \&$ Minori Uchimiya ${ }^{1}$ \\ ${ }^{1}$ USDA-ARS, Southern Regional Research Center, 1100 Robert E Lee Blvd., New Orleans, LA 70124, USA \\ Correspondence: Zhongqi He, USDA-ARS, Southern Regional Research Center, 1100 Robert E. Lee Blvd., New \\ Orleans, LA 70124, USA. Tel: 1-504-286-4516. Fax: 1-(504) 286-4367. E-mail: Zhongqi.He@ars.usda.gov
}

Received: October 21, 2014

Accepted: November 12, $2014 \quad$ Online Published: March 10, 2015

doi:10.5539/mas.v9n4p246

URL: http://dx.doi.org/10.5539/mas.v9n4p246

\begin{abstract}
Biochar is charred material produced by the pyrolysis of organic biomass. In this work, Fourier transform infrared (FTIR) spectra of various agricultural by-products feedstock and their derived biochars were collected to explore the potential of FTIR technique as a simple and rapid method for characterizing their biochar structure. The FTIR information was also discussed for comparing the biochar formation process. Biochars became increasingly more aromatic and carbonaceous with increase in pyrolysis temperature, and these changes could easily be detected from FTIR spectral differences. Complementary to visual inspection of spectral variations, principal component analysis (PCA) of FTIR spectra enhanced the similarity or dissimilarity of biochars prepared at various temperatures. On the basis of spectral features in the $1750-1500 \mathrm{~cm}^{-1}$ region assignable to characteristic carboxyl and aromatic groups that existed in the starting materials and also in biochars, a simple three-band ratio algorithm was developed to monitor the biochar formation semi-quantitatively. Results indicated the feasibility of FTIR in rapid and non-destructive biochar measurements for quality and production.
\end{abstract}

Keywords: biochar, agricultural by-products, Fourier transform infrared spectroscopy, principal component analysis

\section{Introduction}

Biochar is charred material produced by the pyrolysis of any biomass, including such agricultural by-products as wood scraps, grass, cottonseed hulls, wheat straws, corn stovers, and manures (Guo et al., 2012; Keiluweit et al., 2010; Lee et al., 2010; Uchimiya, 2014). It is a form of environmental black carbon, an ubiquitous carbonaceous geosorbent in soils and sediments (Guo et al., 2012; Uchimiya et al., 2010). It has gained great interest as a large-scale soil amendment to enhance soil fertility and sequester soil carbon. The physical and chemical properties of chars vary significantly with the biomass types, pyrolysis conditions, and pre- and post- treatments; however, they consist of similar functional groups that bind cations and porous structures that significantly affect essential soil properties.

Biochar has been analyzed for various functional physical properties and chemical structures through various procedures. Physical and chemical measurements are represented by analyzing surface areas, elemental compositions, moisture, ash, volatile matter, fixed carbon contents, point of zero charge, and metal retention capability (Guo et al., 2012). X-ray diffraction (XRD), scanning electron microscopy (SEM), Fourier transform infrared spectrometry (FTIR), and thermogravimetry/differential thermal analysis (TG/DTA) have also been employed to investigate various aspects of biochars (Guo et al., 2012; Reeves, 2012; Uchimiya, 2014; Uchimiya et al., 2013b). To have a low-cost, rapid, and easy to use method for non-destructive screening of biochars, FTIR spectroscopy could be a possible option. Not only has it been used to obtain highly structural information on various biochars and starting materials, but has also been applied to investigate the structural changes of biochars as a function of pyrolysis temperatures (Keiluweit et al., 2010; Reeves, 2012; Uchimiya et al., 2013a). However, there have been few reports to explore the possibility to compare biochar formation in a semi-qualitative way.

With unique absorptions in the region from 4000 to $600 \mathrm{~cm}^{-1}$, FTIR spectra represent the fundamental absorbance of functional groups in biochars. It is likely that FTIR spectra might detect subtle differences between two biochar samples that could not be distinguished visually, with the aid of multivariate data analysis such as principal component analysis (PCA). PCA is a very effective variable reduction technique for spectroscopic data from $n$ variables (620 in this study) to a fewer number of dimensions (Sanguansat, 2012). It 
decomposes a set of spectra into mathematical spectra (called loading vectors, factors, principal components, etc.) that represent the most common variations to all spectral data. The correlations among samples (or spectra) are indicated by their scores (or projections) on new principal components (PCs). Similar samples tend to be grouped together in the score-score plot, and in turn, atypical samples could be easily detected by the simple visualization.

The objectives of this study were: (1) to examine the unique IR bands between biomass and biochars, (2) to characterize the FTIR spectral response to differing pyrolysis temperatures, and (3) to develop a simple and universal ratio algorithm for semi-qualitative comparison of biochar formation.

\section{Materials and Methods}

\subsection{Starting Materials and Biochar Preparation}

Feedstock property and pyrolysis condition were described in detail in previous reports (Uchimiya et al., 2011, 2013a; Klasson et al., 2014). Briefly, lignin (L25) was obtained from a cellulosic ethanol plant (Örnsköldsvik, Sweden) as wet powder and was air dried (Klasson et al., 2014). Almond (AS25) and pecan (PS25) shells were obtained from shellers and were ground using a SM 2000 cutting mill (Retsch Gmbh, Haan, Germany) and sieved to 0.84-2 mm. Cottonseed hull (CH25) was used as received from Planters Cotton Oil Mill (Pine Bluff, AK) (Uchimiya et al., 2011). Broiler litter (BL25) was obtained from a USDA-ARS facility (Starkville, MS) and was milled and pelletized. Each feedstock was pyrolyzed at $350,500,650$, and $800^{\circ} \mathrm{C}\left(400,500,600,700^{\circ} \mathrm{C}\right.$ for PS25) under 1,600 mL min ${ }^{-1} \mathrm{~N}_{2}$ flow rate for 1-4 h using a laboratory scale box furnace (22 $\mathrm{L}$ void volume) with a retort (Lindberg, Type 51662-HR, Watertown, WI). Biochar products were allowed to cool to room temperature overnight under $\mathrm{N}_{2}$ atmosphere. Biochars are hereby denoted by feedstock abbreviation followed by pyrolysis temperature $\left(25^{\circ} \mathrm{C}\right.$ for unpyrolyzed feedstock), e.g., L25 for lignin feedstock; L350 for lignin biochar produced at $350^{\circ} \mathrm{C}$.

\subsection{ATR-FTIR Spectral Collection and Data Analysis}

All spectra were collected with an FTS 3000MX FT-IR spectrometer (Varian Instruments, Randolph, MA) equipped with a ceramic source, a $\mathrm{KBr}$ beam splitter, and a deuterated triglycine sulfate (DTGS) detector. The attenuated total reflection (ATR) sampling device utilized a DuraSamplIR single-pass diamond-coated internal reflection accessory (Smiths Detection, Danbury, CT), and a consistent contact pressure was applied by way of a stainless steel rod and an electronic load display. Three measurements at different portions of one sample were collected over the range of $4000-600 \mathrm{~cm}^{-1}$ at $4 \mathrm{~cm}^{-1}$ and 16 co-added scans. All samples were ground into powders prior to spectral acquisition. All spectra were in absorbance units and no ATR correction was applied.

Following the import to GRAMS IQ application in Grams/AI (Version 9.1, Thermo Fisher Scientific, Waltham, MA), the spectra were smoothed with a Savitzky-Golay function (polynomial $=2$ and points $=11$ ). Characterization of their PCA was performed in the $1800-600 \mathrm{~cm}^{-1}$ mid-IR region with mean centering (MC) and Savitzky-Golay first-derivative (2 degrees and 13 points) spectral pretreatment. Meanwhile, the spectral set was loaded into Microsoft Excel 2000 to execute simple algorithm analysis.

\section{Results and Discussion}

\subsection{Almond Shell Biochars (AS-chars)}

Figure 1 shows ATR-FTIR spectra of almond shell (AS) and AS-derived biochars at four different pyrolysis temperatures. As expected, with increasing temperature, significant changes occurred in AS-chars in chemical and structural compositions. These changes could be effectively monitored by non-destructive FTIR technique. Band assignments for biochars from various sources have been studied in some details (Reeves, 2012; Uchimiya, 2014; Uchimiya et al., 2013b). Along with the earlier observations, an elevating pyrolysis temperature from 350 to $500{ }^{\circ} \mathrm{C}$ generated a decrease in several characteristic bands, for example, at $3280 \mathrm{~cm}^{-1}(\mathrm{O}-\mathrm{H}$ stretching vibrations of hydrogen bonded hydroxyl groups), 2920 and $2848 \mathrm{~cm}^{-1}$ (asymmetric and symmetric C-H stretching vibrations for aliphatic groups), $1730 \mathrm{~cm}^{-1}$ (carboxyl $\mathrm{C}=\mathrm{O}$ stretching mode), and $1026 \mathrm{~cm}^{-1}$ (symmetric C-O stretching for cellulose, hemicelluloses and lignin). Within this temperature frame of 350 to $500{ }^{\circ} \mathrm{C}$, there are a number of bands whose intensity increased, for instance, the 832 and $700 \mathrm{~cm}^{-1}$ bands (aromatic $\mathrm{C}-\mathrm{H}$ deformation modes), the $1600 \mathrm{~cm}^{-1}$ band (aromatic $\mathrm{C}=\mathrm{C}$ stretching and $\mathrm{C}=\mathrm{O}$ stretching modes of conjugated ketones and quinones), and the $1400 \mathrm{~cm}^{-1}$ band (C-C stretching vibrations in the aromatic ring).

In the higher temperature range of $650-800{ }^{\circ} \mathrm{C}$, the spectra revealed the continuous loss of aromatic groups until the dominance of graphitic C (Bourke et al., 2007). Notably, apparent increase in baseline absorption across the entire spectral region for two AS-chars prepared at higher temperatures $\left(650\right.$ and $\left.800{ }^{\circ} \mathrm{C}\right)$ suggests a production of graphitic $\mathrm{C}$ in nature. 


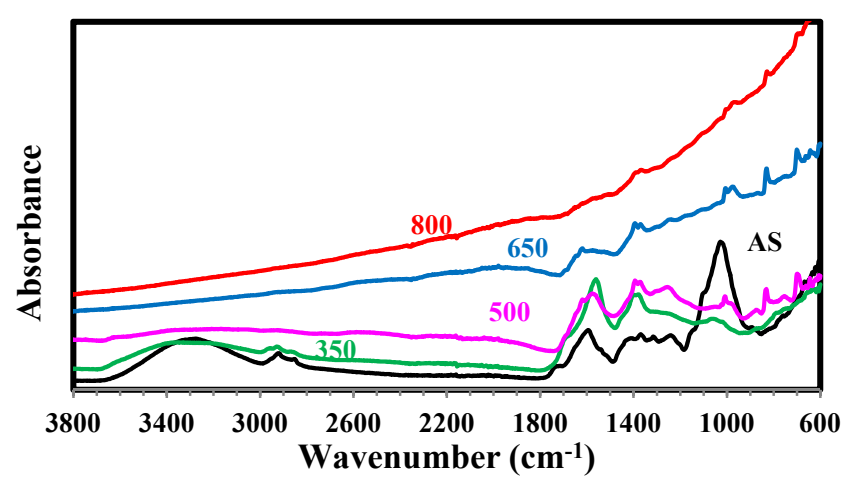

Figure 1. ATR-FTIR spectra of almond shell (AS) and AS-derived biochars made at $350,500,650$, and $800^{\circ} \mathrm{C}$

\subsection{Cottonseed Hull Biochars (CH-chars)}

Despite the various sources, cottonseed hull $(\mathrm{CH})$ exhibits similar ATR-FTIR spectral feature to AS (Figure 2). Obviously, $\mathrm{CH}$ decomposed more rapidly than AS, because of (1) great spectral intensity reduction changes from the starting materials to 350 and then to $500^{\circ} \mathrm{C}$ and (2) unclear occurrence of the bands in the $900-700 \mathrm{~cm}^{-1}$ region due to aromatic $\mathrm{C}-\mathrm{H}$ deformation modes (Figure 2). With no obvious functional groups in the $\mathrm{CH}$-char spectrum prepared at $800^{\circ} \mathrm{C}$ implied that it is essentially graphitic $\mathrm{C}$ in nature. The featureless $\mathrm{CH} 800$ spectrum is typical for activated carbons and pure graphite, and plotting the absorbance at $4393 \mathrm{~cm}^{-1}$ as a function of fixed C content could show an upward baseline shift as illustrated by Uchimiya et al. (2013b).

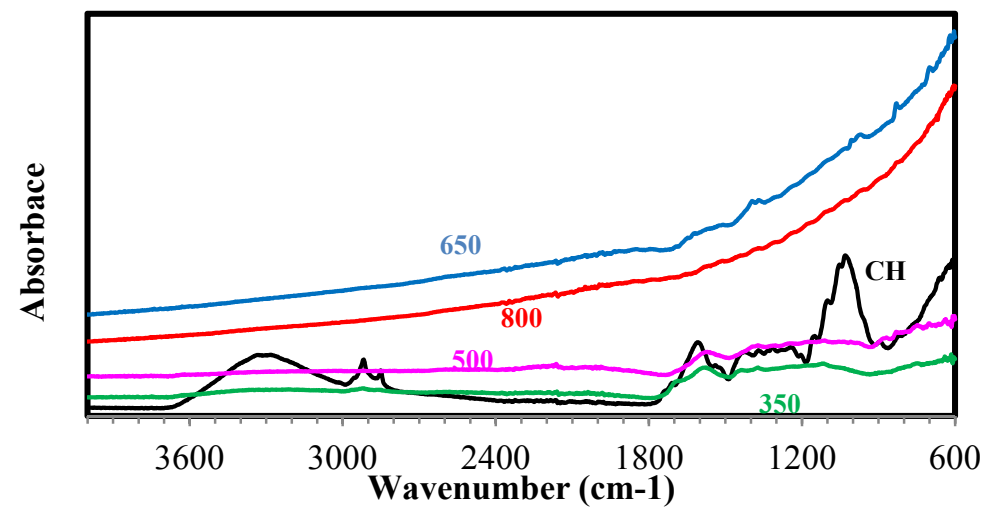

Figure 2. ATR-FTIR spectra of cottonseed hull $(\mathrm{CH})$ and $\mathrm{CH}$-derived biochars made at $350,500,650$, and $800^{\circ} \mathrm{C}$

\subsection{Pecan Shell Biochars (PS-chars)}

Spectrum of pecan shell (PS) is quite similar to the AS and CH spectra (Figure 3); however, it has a distinctive band at $1740 \mathrm{~cm}^{-1}$ attributable to carboxyl $\mathrm{C}=\mathrm{O}$ groups. As shown in Figure 4, PS-chars produced from 350 to $650^{\circ} \mathrm{C}$ closely resembled those respective $\mathrm{CH}$-chars, besides the pronounced band at $872 \mathrm{~cm}^{-1}$. Meanwhile, a $50^{\circ} \mathrm{C}$ difference in pyrolysis temperature (650 vs. 700$)$ made a great difference in the formation of graphite-like PS-char. 


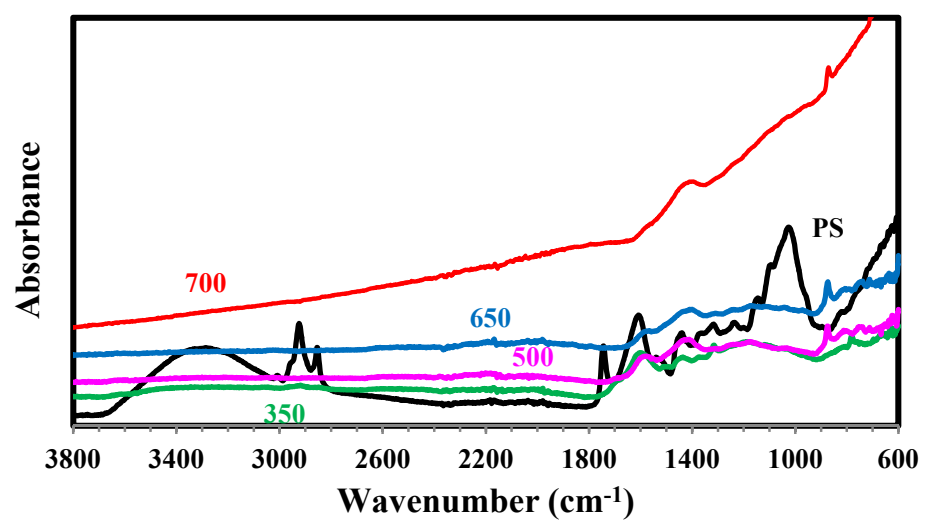

Figure 3. ATR-FTIR spectra of pecan shell (PS) and PS-derived biochars made at $350,500,650$, and $700^{\circ} \mathrm{C}$

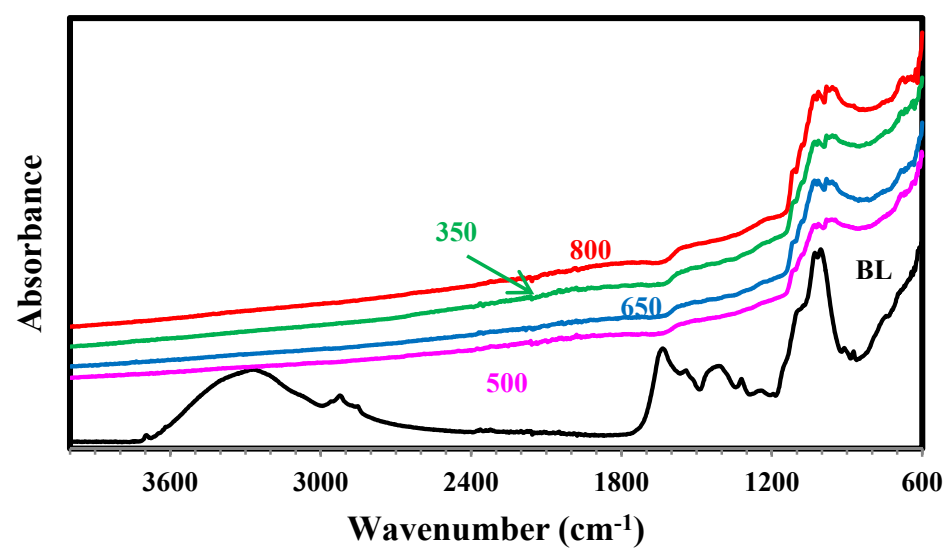

Figure 4. ATR-FTIR spectra of broiler litter (BL) and BL-derived biochars made at $350,500,650$, and $800^{\circ} \mathrm{C}$

\subsection{Broiler Litter Biochars (BL-chars)}

Broiler litter (BL) is a mixture of poultry excreta, spilled feed, feathers, and bedding materials as wood shavings, sawdust, peanut hulls, and etc. (Guo et al., 2012). Its spectrum is much close to AS and CH spectra (Figure 4), with a pronounced band at $1635 \mathrm{~cm}^{-1}$ due to protein carboxyl $\mathrm{C}=\mathrm{O}$ groups. Comparing the spectra for BL-chars in Figure 4 to those in Figure1, 2 and 3, one can see many disparities that originated from different starting materials as the BL-chars were completely different from starting material-BL. On the other hand, they were similar to each other by sharing strong and broad bands at 1025 and $970 \mathrm{~cm}^{-1}$ (Figure 4). The functional groups in this region are generally assigned to alcoholic and polysaccharide $\mathrm{C}-\mathrm{O}$ stretching, silicate and phosphate vibrations (He et al., 2009; He and Ohno, 2012). As alcoholic and polysaccharide would have degraded at the high pyrolysis temperature and a high phosphate content in BL, the bands at 1025 and $970 \mathrm{~cm}^{-1}$ should be due to mineral phosphate residues in these biochars (He et al., 2006). Otherwise, the similarity in the spectral features of the four BL biochars suggested that $350^{\circ} \mathrm{C}$ was high enough to completely carbonize organic compounds in BL. It is worth noting that the observation on the indifference in the spectral features between these BL biochars is not consistent with the previous observation (Uchimiya et al., 2010) in which BL350 had more FTIR peaks than BL700. The inconsistency might be due to the high inhomogeneity of broiler litter samples or to variation in the FTIR sample preparation. On the other hand, Uchimiya et al. (2010) did report more similar spectral features between BL350 and BL700 after steam activation at $800^{\circ} \mathrm{C}$.

\subsection{Lignin Biochars (LN-chars)}

This so-called lignin sample was not really "lignin" as it comes from a biorefinery after making bioethanol from lignocellulose. Such "Lignin" residue (2-100 $\mathrm{mm}$ sized dark brown powder) from bioethanol production plant can contain as much as $49.5 \mathrm{wt} \%$ of sparingly water-soluble cellulose crystals, in addition to $42.1 \mathrm{wt} \%$ lignin and $8.4 \mathrm{wt} \%$ extractives (Uchimiya et al., 2013a). Additional wood hydrolysis co-products are furfuryl, phenolic, epoxy, and isocyanate resins. Its spectral signature indicates that it contains significant $\mathrm{C}-\mathrm{O}$ groups (due to 
intense $1025 \mathrm{~cm}^{-1}$ band) but less amide and $\mathrm{C}=\mathrm{O}$ groups (due to weak bands in the $1800-1600 \mathrm{~cm}^{-1}$ region) (Figure 5). With pyrolysis temperature progressing, LN-chars exhibited the similar spectral variations as AL-chars, PS-chars, and CH-chars.

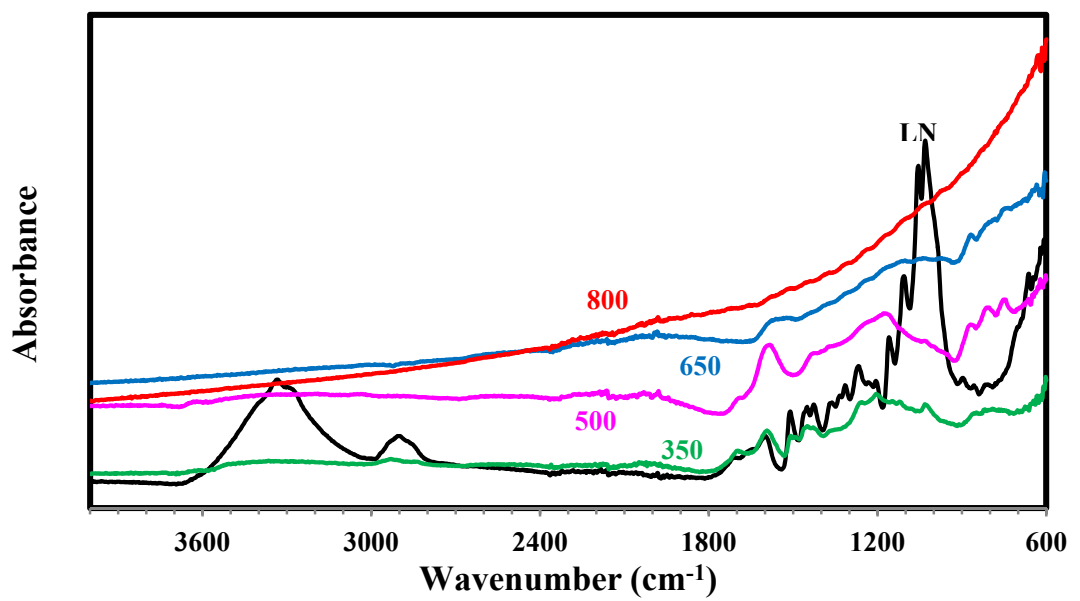

Figure 5. ATR-FTIR spectra of lignin (LN) and LN-derived biochars made at $350,500,650$, and $800^{\circ} \mathrm{C}$

\subsection{PCA of ATR-FTIR Spectra}

PCA is a useful tool for identifying samples that possess similar properties. Meszaros et al. (2007) used the characteristic peaks of thermogravimetry-mass spectrometry and the amounts of the most important volatile products as input data for the PCA analysis of a wide variety of biomass charcoals (typically formed at temperatures below $800^{\circ} \mathrm{C}$ ). Their PCA results showed that the amount of volatile compounds of a biochar is the key determinant of its thermal properties as quantified by thermogravimetry-mass spectrometry. In this work, as one approach to interpret the spectral intensity variation observed Figure 1 through 5, all spectra were subjected to PCA characterization in the $1800-600 \mathrm{~cm}^{-1}$ region with full cross validation method. The first nine PCs accounted for $95.0 \%$ of the total variation, with the first PC (PC1), the second PC (PC2) and the third PC (PC3) explaining $28.2 \%, 19.2 \%$, and $13.2 \%$ of the spectral variation, respectively. The plot of PC1 vs. PC3 scores provided a better subjective visualization of separation among five set of samples than such a combination as PC1 vs. PC2, and a representative plot is given in Figure 6. It reveals that the samples could be distinguished at some degree by the magnitude of pyrolysis temperature with the use of a sole PC1 score (horizontal axis), which is within the line of expectation, as mid-IR spectroscopy is an excellent and rapid method for characterizing both starting materials and the resulting biochars (Reeves, 2012).

Combined with $\mathrm{PC} 1>0, \mathrm{PC} 3$ scores along the vertical axis differentiated the respective biochars obtained at $300-500$ and $600-800^{\circ} \mathrm{C}$. For example, among 12 samples prepared at relatively low temperatures from $300-500^{\circ} \mathrm{C}$, there were 10 samples that had negative $\mathrm{PC} 3(\mathrm{PC} 3<0)$ values, while within 10 samples prepared at higher temperatures from $600-800^{\circ} \mathrm{C}$, there were 8 samples that had positive $\mathrm{PC} 3(\mathrm{PC} 3>0)$ values. In other words, the number of biochar samples with both positive PC1 and PC3 scores increased as pyrolysis temperature increased from $300-500$ to $600-800^{\circ} \mathrm{C}$. The result suggested that generally, with increasing temperature, the biochars had a tendency to be positive on PC1 and PC3, independent of starting materials. 


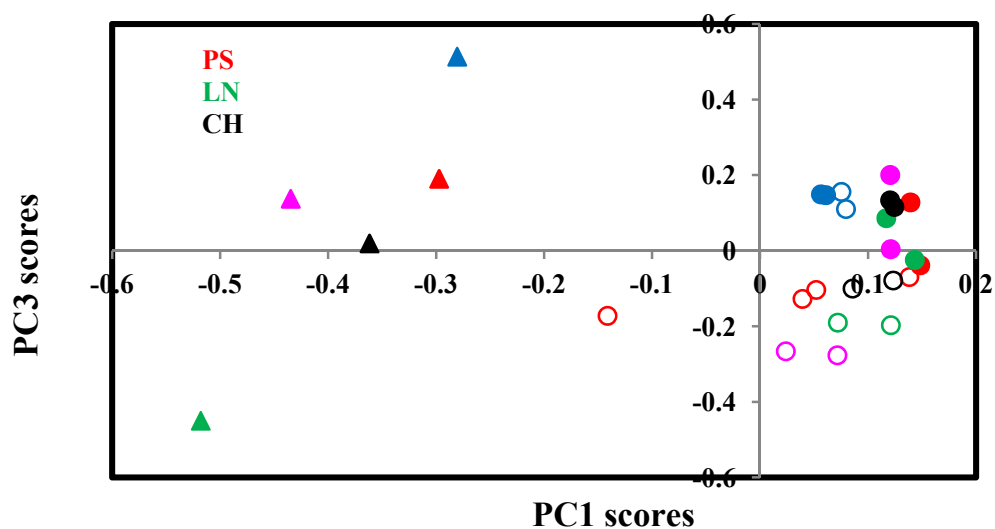

Figure 6. PC1 vs. PC3 score-score plot of starting materials (in filled triangles) and respective biochars made at $300-500^{\circ} \mathrm{C}$ pyrolysis temperature (in open circles) and at $600-800^{\circ} \mathrm{C}$ pyrolysis temperature (in filled circles); PS and PS-chars in red colored symbols, $\mathrm{LN}$ and LN-chars in green colored symbols, $\mathrm{CH}$ and $\mathrm{CH}$-chars in black colored symbols, BL and BL-chars in blue colored symbols, and AS and AS-chars in pink colored symbols

\subsection{Algorithm for Characterizing ATR-FTIR Spectra of Starting Materials and Biochars}

The above observations suggest that spectral distinctions between starting materials and biochars as well as within biochars prepared at various pyrolysis temperatures might be useful for their comparison. Therefore, it is of interest to examine whether these samples could be distinguished semi-quantitatively based on a spectral intensity difference. We developed a simple 3-band algorithm (R) in Eq. 1.

$$
\mathrm{R}=\left(\mathrm{A}_{1700}-\mathrm{A}_{1800}\right) /\left(\mathrm{A}_{650}-\mathrm{A}_{1800}\right)
$$

where $R$ represents the intensity ratio and $A_{1700}, A_{1800}$, and $A_{650}$ each are a multi-point average of the band intensities at respective range of $1750-1500 \mathrm{~cm}^{-1}, 2000-1790 \mathrm{~cm}^{-1}$, and $645-655 \mathrm{~cm}^{-1}$. The bands in the $1750-1500 \mathrm{~cm}^{-1}$ range originate from $\mathrm{C}=\mathrm{O}$ and amide characteristic groups that are common in both starting materials and biochars, hence they can be used to monitor the biochar formation process. Relative to the greater intensity in the $645-655 \mathrm{~cm}^{-1}$ range, minimum absorbance of the bands in the $2000-1790 \mathrm{~cm}^{-1}$ region was selected to be zero subjectively.

The algorithm was applied to ATR-FTIR spectral set consisting of raw materials and biochars, and the plot of R against pyrolysis temperature is shown in Figure 7. Notably, there were not clear correlations between $R$ and pyrolysis temperature for individual material, which is not unexpected given the dynamic equilibrium between the production of carboxyl and amide groups and their further decomposition. In general, $\mathrm{R}$ values increased initially and then decreased with pyrolysis temperature increasing for all materials but BL. R readings were in the range of 0.65 and 0.20 for biochars (excluding BL derived) prepared at lower pyrolysis temperatures (300 to $\left.500^{\circ} \mathrm{C}\right)$ and 0.11 to 0.03 for biochars processed at higher temperatures $\left(600\right.$ to $\left.800^{\circ} \mathrm{C}\right)$. The results also suggested that $\mathrm{BL}$ has become the graphite-dominant even before reaching the temperature of $300^{\circ} \mathrm{C}$. Probably, $\mathrm{BL}$, a poultry digested waste, contains mainly smaller molecules that were much easily to be decomposed and oxidized. 


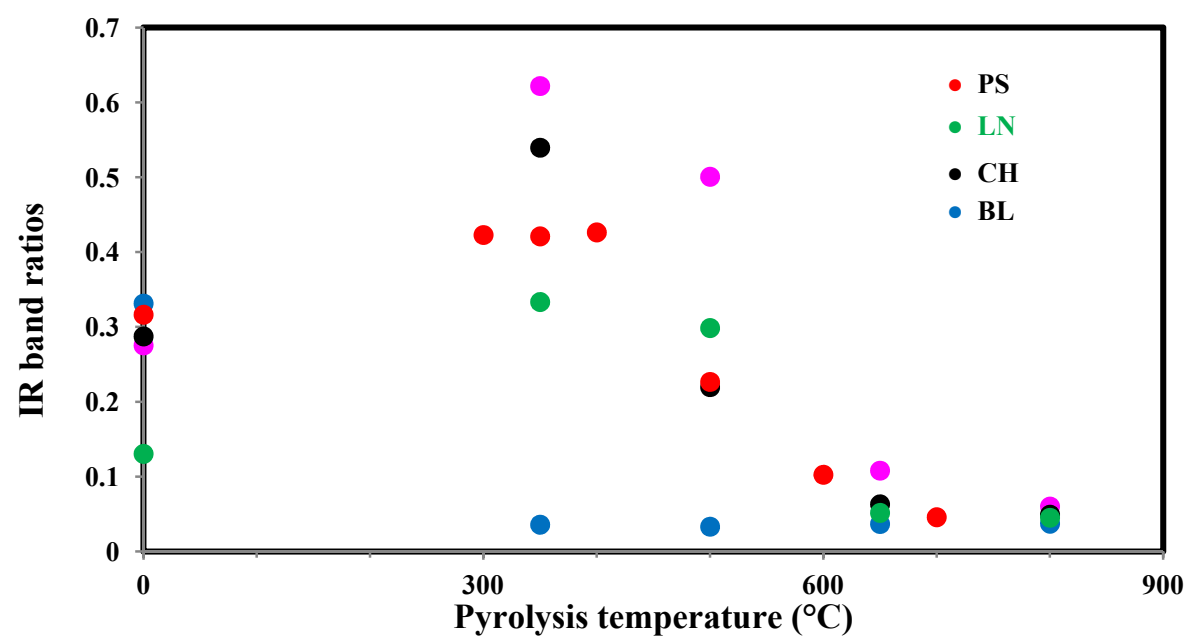

Figure 7. Plot of R values vs. pyrolysis temperatures. PS and PS-chars in red colored symbols, LN and LN-chars in green colored symbols, $\mathrm{CH}$ and $\mathrm{CH}$-chars in black colored symbols, BL and BL-chars in blue colored symbols, and AS and AS-chars in pink colored symbols

\section{Conclusion}

This study demonstrates the usefulness and effectiveness of FTIR spectroscopy in rapid, non-destructive, and direct measurement of biochar formation. With pyrolysis temperature rising, biochars underwent a number of significant changes in chemical, physical, and structural aspects. These changes can easily be revealed by FTIR spectra of samples. Principal component analysis of FTIR spectra indicated distinctions of biochars manufactured at various pyrolysis temperatures. A simple algorithm involving the $1750-1500 \mathrm{~cm}^{-1}$ characteristic bands of FTIR spectra was further developed to describe the biochar formation. The results suggest that FTIR technique can be used as an efficient tool to control biochar quality through production condition manipulation.

\section{Acknowledgments}

Mention of trade names or commercial products in this publication is solely for the purpose of providing specific information and does not imply recommendation or endorsement by the U.S. Department of Agriculture. USDA is an equal opportunity provider and employer.

\section{References}

Bourke, J., Manley-Harris, M., Fushimi, C., Dowaki, K., Nunoura, T., \& Antal, M. J. (2007). Do all carbonized charcoals have the same chemical structure? 2. A model of the chemical structure of carbonized Charcoal. Ind. Eng. Chem. Res., 46, 5954-5967. http://dx.doi.org/10.1021/ie070415u

Guo, M., Shen, Y., \& He, Z. (2012). Poultry litter-based biochar: preparation, characterization, and utilization. In He, Z. (Ed.), Applied Research of Animal Manure: Challenges and Opportunities beyond the Adverse Environmental Concerns. Nova Science Publishers, Inc., New York, pp. 171-102.

He, Z., Honeycutt, C. W., Zhang, T., \& Bertsch, P. M. (2006). Preparation and FT-IR characterization of metal phytate compounds. J. Environ. Qual., 35, 1319-1328. http://dx.doi.org/10.2134/jeq2006.0008

He, Z., Mao, J., Honeycutt, C. W., Ohno, T., Hunt, J. F., \& Cade-Menun, B. J. (2009). Characterization of plant-derived water extractable organic matter by multiple spectroscopic techniques. Biol. Fertil. Soils., 45, 609-616. http://dx.doi.org/10.1007/s00374-009-0369-8

He, Z., \& Ohno, T. (2012). Fourier transform infrared and fluorescence spectral features of organic matter in conventional and organic dairy manure. J. Environ. Qual., 41, 911-919. http://dx.doi.org/10.2134/jeq2011.0226

Keiluweit, M., Nico, P. S., Johnson, M. G., \& Kleber, M. (2010). Dynamic molecular structure of plant biomass-derived black carbon (biochar). Environ. Sci. Technol., 44, 1247-1253. http://dx.doi.org/10.1021/es9031419

Klasson, K. T., Boihem, Jr, L. L., Uchimiya, M., \& Lima, I. M. (2014). Influence of biochar pyrolysis 
temperature and post-treatment on the uptake of mercury from flue gas. Fuel Process. Technol., 123, 27-33. http://dx.doi.org/10.1016/j.fuproc.2014.01.034

Lee, J. W., Kidder, M., Evans, B. R., Paik, S., Buchanan, A. C., Garten, C. T., \& Brown, R. C. (2010). Characterization of biochars produced from cornstovers for soil amendment. Environ. Sci. Technol., 44, 7970-7974. http://dx.doi.org/10.1021/es101337x

Meszaros, E., Jakab, E., Varhegyi, G., Bourke, J., Manley-Harris, M., Nunoura, T., \& Antal, M. J. (2007). Do all carbonized charcoals have the same chemical structure? 1. Implications of thermogravimetry-mass spectrometry measurements. Ind. Eng. Chem. Res., 46, 5943-5953. http://dx.doi.org/10.1021/ie0615842

Reeves, J. (2012). Mid-infrared spectroscopy of biochars and spectral similarities to coal and kerogens: what are the implications? Appl. Spectr., 66, 689-695. http://dx.doi.org/10.1366/11-06478

Sanguansat, P. (ed.). (2012). Principal component analysis - engineering applications. Intech, Rijeka, Croatia.

Uchimiya, M. (2014). Changes in nutrient content and availability during the slow pyrolysis of animal wastes. In He, Z., \& Zhang, H. (Eds.), Applied Manure and Nutrient Chemistry for Sustainable Agriculture and Environment (pp. 53-68). Springer, Amsterdam, Netherlands. http://dx.doi.org/ 10.1007/978-94-017-8807-6_3

Uchimiya, M., Lima, I. M., Klasson, K. T., Chang, S. C., Wartelle, L. H., \& Rodgers, J. E. (2010). Immobilization of heavy metal ions (Cu-II, Cd-II, Ni-II, and Pb-II) by broiler litter-derived biochars in water and soil. J. Agric. Food Chem., 58, 5538-5544. http://dx.doi.org/10.1021/jf9044217

Uchimiya, M., Ohno, T., \& He, Z. (2013a). Pyrolysis temperature-dependent release of dissolved organic carbon from plant, manure, and biorefinery wastes. J. Anal. Appl. Pyroly., 104, 84-94. http://dx.doi.org/10.1016/j.jaap.2013.09.003

Uchimiya, M., Orlov, A., Ramakrishnan, G., \& Sistani, K. R. (2013b). In situ and ex situ spectroscopic monitoring of biochar's surface functional groups. J. Anal. Appl. Pyrol., 102, 53-59. http://dx.doi.org/10.1016/j.jaap.2013.03.014

Uchimiya, M., Wartelle, L. H., Klasson, K. T., Fortier, C. A., \& Lima, I. M. (2011). Influence of pyrolysis temperature on biochar property and function as a heavy metal sorbent in soil. J. Agric. Food Chem., 59, 2501-2510. http://dx.doi.org/10.1021/jf104206c

\section{Copyrights}

Copyright for this article is retained by the author(s), with first publication rights granted to the journal.

This is an open-access article distributed under the terms and conditions of the Creative Commons Attribution license (http://creativecommons.org/licenses/by/3.0/). 